\begin{tabular}{|l|l|}
\hline Title: & $\begin{array}{l}\text { Effect of load distribution and variable depth on shear resistance of slender } \\
\text { beams without stirrups }\end{array}$ \\
\hline Authors: & Pérez Caldentey A., Padilla P., Muttoni A., Fernández Ruiz M. \\
\hline Published in: & ACI Structural Journal \\
\hline $\begin{array}{l}\text { Volume: } \\
\text { Pages: }\end{array}$ & $\begin{array}{l}\text { V. } 109 \\
\text { pp. } 595-603\end{array}$ \\
\hline Country: & USA \\
\hline Year of publication: & 2012 \\
\hline Type of publication: & Peer reviewed journal article \\
\hline
\end{tabular}

Please quote as:

Pérez Caldentey A., Padilla P., Muttoni A., Fernández Ruiz M., Effect of load distribution and variable depth on shear resistance of slender beams without stirrups, ACI Structural Journal, V. 109, USA, 2012, pp. 595-603. 


\title{
Effect of Load Distribution and Variable Depth on Shear Resistance of Slender Beams without Stirrups
}

\author{
by Alejandro Pérez Caldentey, Patricio Padilla, Aurelio Muttoni, and Miguel Fernández Ruiz
}

The shear resistance of elements without stirrups has mainly been investigated by test setups involving simply supported beams of constant thickness subjected to one- or two-point loading, and most of the formulas included in codes have been adjusted using this experimental background. It is a fact, however, that most design situations involve constant or triangular distributed loading (such as retaining walls or footings) on tapered members. Furthermore, there seems to be few shear tests involving cantilever structures subjected to distributed loading. These structures, which are common in everyday practice, fail in shear near the clamped end, where the shear forces and bending moments are maximum (contrary to simply supported beams of tests, where shear failures under distributed loading develop near the support region for large shear forces but limited bending moments).

In this paper, a specific testing program undertaken at the Polytechnic University of Madrid (UPM), Madrid, Spain, in close collaboration with Ecole Polytechnique Fédérale de Lausanne (EPFL), Lausanne, Switzerland, is presented. It was aimed at investigating the influence of load distribution and tapered beam geometrics on the shear strength. The experimental program consists of eight slender beams without stirrups. Four specimens had a constant depth, whereas the others had variable depths (maximum depth of $600 \mathrm{~mm}$ [23.6 in.]). Each specimen was tested twice: one side was tested first under point loading, and then (after repairing) the other side was tested under either uniform loading or triangular loading. The setup allowed direct comparisons between point and distributed loading. The experimental results showed a significant influence of the type of loading and of tapered geometries on the shear strength. On the basis of these results, and using the fundamentals of the critical shear crack theory, a consistent physical explanation of the observed failure modes and differences in shear strength is provided. Also, comparisons to current design provisions (ACI 318-08 and EC2) are discussed.

Keywords: cantilevers; critical shear crack theory; load distribution; reinforced concrete; shear strength; shear tests; stirrups; variable depth.

\section{INTRODUCTION}

Most one-way slabs and similar members in practice are subjected to distributed loading. These members are usually without shear reinforcement and, in many cases, their design is governed by shear. This is the case, for instance, for retaining walls, footings, earth-covered structures, or silos (Fig. 1(a) to (d)), as well as the support regions of some tapered slab bridges (Fig. 1(e)) and deck slabs of girder bridges (Fig. 1(f)). These members are typically cantilevers or continuous slabs and usually have tapered geometries. This is contrary to most research performed on shear in members without transverse reinforcement, where specimens typically correspond to simply supported beams with constant thickness and are subjected to point loading.

Some research has been performed on specimens subjected to distributed loading. ${ }^{1-7}$ However, they mostly focused on simply supported beams of constant thickness, where shear failures develop close to the supports. Failures thus develop with relatively large shear forces but with rather limited bending moments, which may not be suitable to reproduce failure zones of cantilevers or continuous members ${ }^{8}$ (with the potential failure sections in shear, subjected to maximum shear and bending moments simultaneously). With respect to research performed on tapered members without shear reinforcement, ${ }^{9-11}$ it deals mostly with specimens subjected to point loading.

This fact raises the question of whether design models not based on mechanical models and calibrated on the basis of existing tests (such as EC2 ${ }^{12}$ or ACI $318-08^{13}$ ) are suitable to account for a series of significant effects on shear strength, such as:

- The strains (or crack widths) limiting shear strength ${ }^{8}$ and actually developing on the shear-critical region of cantilevers (whose shear and bending moments may differ significantly from those of simply supported beams);

- The amount of shear that can be carried by the inclination of the compression chord in tapered members;

- The influence of loads applied near supports. As shown in Kani et al. ${ }^{14}$ for concentrated loads applied near supports (at a distance smaller than $2.5 d$ to $3 d$ ), the shear strength of members without transverse reinforcement increases significantly (Fig. 2(a)). This is due to the fact that, for short-span beams, the critical shear crack develops mostly without disturbing the shear-critical region (strut carrying shear ${ }^{8}$ ). The case of slender beams with distributed loads is potentially different, however, as the critical shear crack (shape and location) is not only influenced by the loads applied near the support but also by the rest of the distributed loads.

These effects can significantly influence shear strength. Some of them (direct strut action and inclination of compression chord) may increase shear strength and allow one to avoid placing unnecessary shear reinforcement. Others (actual crack widths and some cases of inclined tension/compression chords) may reduce shear strength with respect to design code predictions and potentially lead to unsafe designs.

In a general manner (for members with or without transverse reinforcement), the shear strength can be calculated, accounting for these contributions, as

$$
V_{R}=V_{c}+V_{s}+V_{\text {dir }}+V_{\text {chord }}
$$

ACI Structural Journal, V. 109, No. 5, September-October 2012

MS No. S-2010-218.R2 received November 17, 2011, and reviewed under Institute publication policies. Copyright (C) 2012, American Concrete Institute. All rights reserved, including the making of copies unless permission is obtained from the copyright proprietors. Pertinent discussion including author's closure, if any, will be published in the July-August 2013 ACI Structural Journal if the discussion is received by March 1, 2013 
Alejandro Pérez Caldentey is a Professor of structural concrete at the Civil Engineering School of the Polytechnic University of Madrid (UPM), Madrid, Spain, and Head of the Research, Development and Innovation Department of FHECOR Consulting Engineers, Spain. He received his engineering degree and his PhD from UPM in 1989 and 1996, respectively.

Patricio Padilla is a Project Engineer at FHECOR Consulting Engineers. He received his civil engineering degree from the National University of Tucumán, Argentina, and his PhD from UPM.

ACI member Aurelio Muttoni is a Professor and Head of the Structural Concrete Laboratory at the Ecole Polytechnique Fédérale de Lausanne (EPFL), Switzerland. His research interests include the theoretical basis of the design of reinforced concrete structures, shear and punching shear, fiber-reinforced high-strength concrete, soilstructure interaction, and the conceptual design of bridges. He received the ACI Chester Paul Siess Award for Excellence in Structural Research in 2010.

Miguel Fernández Ruiz is a Lecturer and Research Scientist at EPFL. He received his diploma in civil engineering and his PhD from UPM in 2001 and 2004, respectively. His research interests include the serviceability behavior of structures, bond, shear, and the modeling of structural concrete using stress fields.

where $V_{R}$ is the total shear strength; $V_{c}$ is the shear force carried by concrete (due to aggregate interlock or concrete tensile strength $\left.{ }^{8,15}\right) ; V_{s}$ is the shear carried by transverse reinforcement; $V_{d i r}$ is the fraction of the loads carried by direct strut action; and $V_{\text {chord }}$ is the shear carried by the inclination of the chords.

For members with sufficient shear reinforcement, the contribution of concrete to the shear strength can be neglected $^{15}\left(V_{c} \approx 0\right)$ or taken into account indirectly by using flatter angles for the struts. The rest of the shear-carrying components can be easily assessed in this case on the basis of a physical model as, for instance, a stress field (Fig. 2(b)) and its corresponding free-body diagram (Fig. 2(c)). For uniformly distributed loading, the result is

$$
V_{d i r}=q \cdot a_{d i r}
$$

where $q$ is the uniformly distributed load; and $a_{d i r}$ is the length where loads are carried by direct strut action.

$$
V_{\text {chord }}=\frac{M}{z} \tan (\delta) \cdot \frac{1-\frac{a_{d i r}}{2 a}}{1-\frac{a_{d i r}}{2 z} \tan (\delta)}
$$

where $M$ is the bending moment at the face of the support; $z$ is the inner lever arm at this section; and $\delta$ is the slope of the soffit of the member. On the basis of Eq. (3a), $V_{\text {chord }}$ is usually approximated for the design of slender members $\left(a_{d i r}\right.$ $<<a, \tan (\delta)<<1)$ as

$$
V_{\text {chord }}=\frac{M}{z} \tan (\delta)
$$

For members without shear reinforcement $\left(V_{s}=0\right)$, the shear force that can be carried by concrete $\left(V_{c}\right)$ depends mostly on the concrete compressive strength and on the opening of the cracks in the shear-critical region ${ }^{8}$ (which can be evaluated by means of strain-based models ${ }^{8}$ or by using empirical formulas ${ }^{12,13}$ ). With respect to the other contributions, most design approaches ${ }^{12,13}$ usually provide a means of accounting for $V_{d i r}$. In many cases, however, the calculation of $V_{\text {chord }}$ is not clearly defined (choice of control section), or no physical model (allowing a physical understanding as the one for members with transverse reinforcement shown in Fig. 2(b) and (c)) is provided to do so.

The authors of this paper have previously investigated the shear strength of members without transverse reinforcement providing a general approach based on the critical shear crack theory ${ }^{8}$ (CSCT). This investigation showed the suitability and consistency of a strain-based model to calculate shear strength for members subjected to point or to distributed loading. Also, the influence of concentrated loads on shear failures of tapered cantilever slabs (Fig. 1(f)) was investigated on the basis of the same theory with excellent results. ${ }^{16}$ In this study, the authors present the results of a specific experimental program on the shear strength of (a)

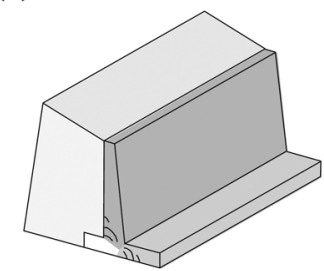

(d)

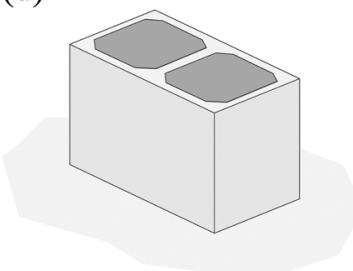

(b)

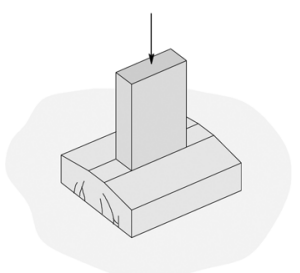

(e)

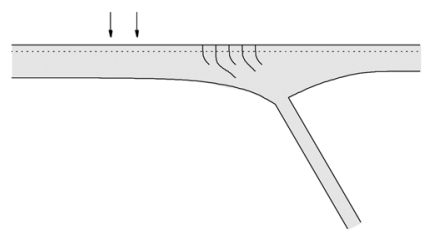

(c)

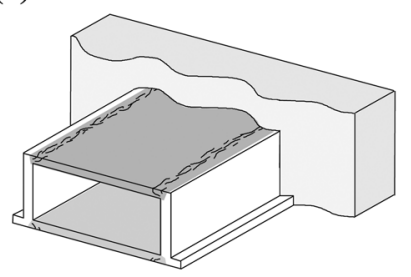

(f)

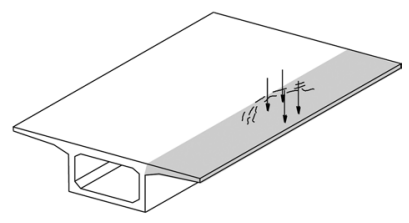

Fig. 1-Examples of one-way slabs and similar members without stirrups: (a) retaining wall; (b) foundation; (c) cut-and-cover tunnel; (d) silo; (e) tapered support region of a slab frame bridge; and $(f)$ deck slab of box girder bridge. 
slender cantilevers subjected to distributed loading (approximated by eight concentrated loads). The aim was to provide experimental data on a domain where few tests are available and develop a rational model that accounts for the influence of strains at the shear-critical region on shear strength, the effect of direct strut action on loads near the supports, and the contribution of the inclined compression chords to shear strength. The experimental results are compared to code provisions (EC2 $2^{12}$ and ACI $318-08^{13}$ ) and the CSCT, allowing a better explanation and understanding of the behavior of the various shear-transfer actions.

\section{RESEARCH SIGNIFICANCE}

Shear is the governing failure mode in many structural members without stirrups subjected to distributed loading, such as retaining walls, footings, and top slabs of earthcovered structures. The design formulas of many codes of practice, however, are based on tests of simply supported beams subjected to point loading. In addition, most available tests have been performed on constant-thickness specimens, whereas the depth of the members is often variable in actual structures. For empirical models based on such an experimental background, this may imply that some effects significantly influencing shear strength (such as the state of strains at the shear-critical region, the direct strut action of loads near supports, or the shear carried by the inclination of the compression chord) may not be properly accounted for. In many cases, this leads to placement of unnecessary shear reinforcement or, potentially, to unsafe designs. This study presents the results of a test series on reinforced concrete (RC) slender cantilevers that allows a direct comparison between the shear strength of members subjected to a single load or to distributed loading for both constant-thickness or tapered beams. The experimental results are consistently explained on the basis of the CSCT and compared to various shear models.

\section{Specimens}

\section{EXPERIMENTAL INVESTIGATION}

Eight reinforced concrete specimens were tested under four load configurations (each load configuration was tested using two specimens). The investigated parameters were: 1) influence of load distribution (point loading, uniform loading, and triangular loading); and 2) influence of variable depth.

Figure 3 shows the geometry of the four different types tested. The specimens were named as follows:

- CR1/CR2: Constant depth and uniformly distributed load (Fig. 3(a));

- CT1/CT2: Constant depth and triangular load (Fig. 3(b));

- VR1/VR2: Variable depth and uniformly distributed load (Fig. 3(c)); and

- VT1/VT2: Variable depth and triangular load (Fig. 3(d)).

To avoid bending failure prior to shear failure and to keep the reinforcement ratio within reasonable limits for elements designed without shear reinforcement, high-strength steel bars with a nominal characteristic yield stress of $835 \mathrm{MPa}$ $(121 \mathrm{ksi})$ were used as tensile reinforcement. To avoid anchorage failures, steel plates were provided at both ends of the main reinforcing bars (refer to Fig. 4). The reinforcement of all specimens was identical, consisting of two $26.5 \mathrm{~mm}$ (1.04 in.) bars on the tensile face. On the compression face, two $12 \mathrm{~mm}(0.47 \mathrm{in}$.) ordinary bars consisting of mild reinforcement steel with a nominal characteristic yield stress of $500 \mathrm{MPa}$ (72.5 ksi) were placed (refer to Fig. 4). (a)

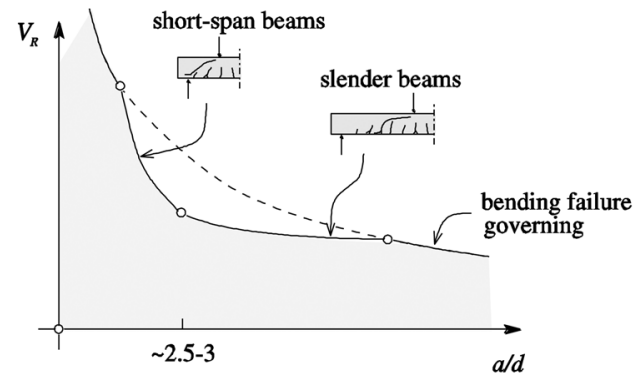

(b)

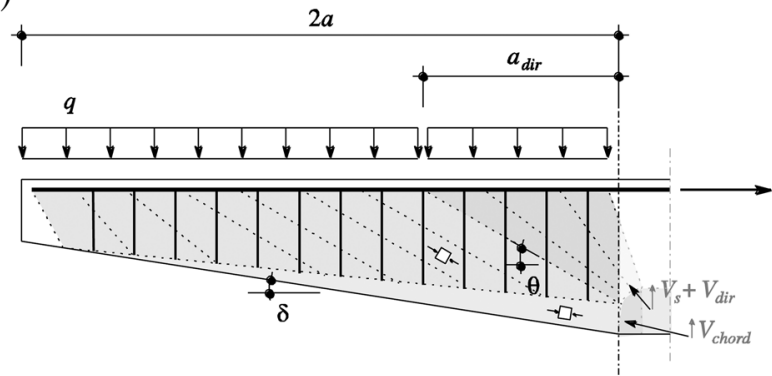

(c)

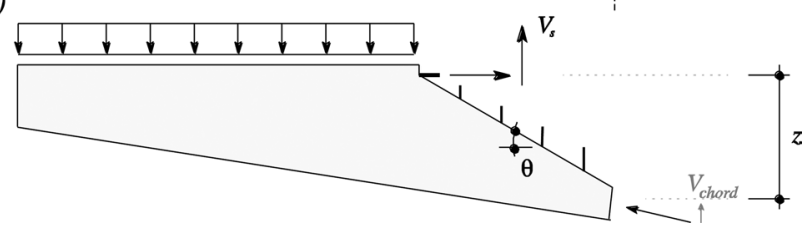

Fig. 2-Influence of slenderness and inclination of compression chord on shear strength: (a) Kani's valley for members without transverse reinforcement; (b) stress field at support region of tapered members with shear reinforcement; and (c) free-body diagram corresponding to previous stress field.

Concrete cover for all specimens was $25 \mathrm{~mm}$ (1 in.) with an effective depth $d$ at the clamped section equal to $562 \mathrm{~mm}$ (22.1 in.) and a reinforcement ratio $\rho\left(=A_{s} /\left(b_{w} d\right)\right)$ equal to $0.79 \%$ for all specimens.

The geometry of the specimens was selected so that the center of gravity of the applied loads remains the same in all cases, with a constant ratio between the resultant of the applied forces and the effective depth (a/d) equal to 2.75 . Each specimen was tested on both sides, allowing for a direct comparison of the shear strength of concentrated and distributed loading. The specimen was loaded on the long cantilever side with eight forces simulating a distributed load (applied through $160 \times 80 \mathrm{~mm}$ [6.3 x 3.2 in.] neoprene pads) and supported on a steel plate (supporting surface equal to $210 \times 250 \mathrm{~mm}$ [8.3 x $9.8 \mathrm{in}$.]). As a result, a point load reaction developed at the short cantilever (introduced through a steel plate of $200 \times 250 \times 20 \mathrm{~mm}$ [7.87 x $7.87 \times$ $0.78 \mathrm{in}]$.$) . For tests under uniform load, the weight of the$ loading arrangement in the long cantilever was $4.0 \mathrm{kN}$ (0.9 kips), whereas for tests under triangular load, the weight of the loading arrangement in the long cantilever was $5.9 \mathrm{kN}$ (1.33 kips). All specimens developed shear failure within the short cantilever in the first phase of the test. Thereafter, the failure zone was repaired using three sets of two steel plates (one placed on the top and the other on the bottom side of the beam and tied together by means of four mild steel $12 \mathrm{~mm}$ [0.47 in.] bars) and the long cantilever was loaded again until failure developed within the longer cantilever. The distance between the eight loads on the long cantilever as well as their 
(a)

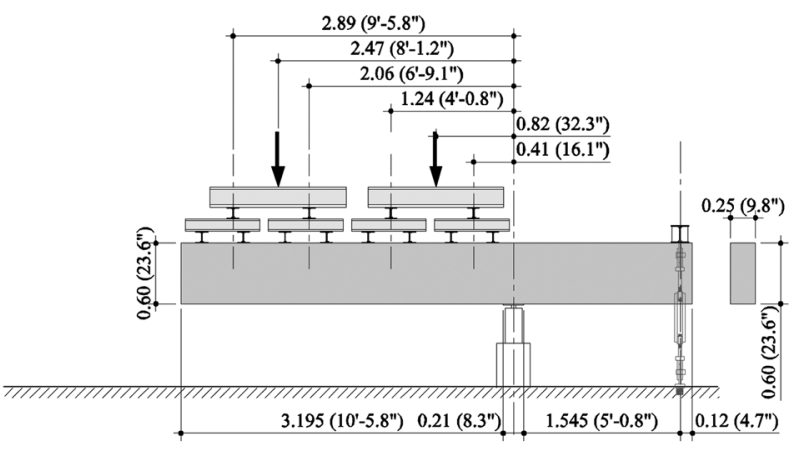

(b)

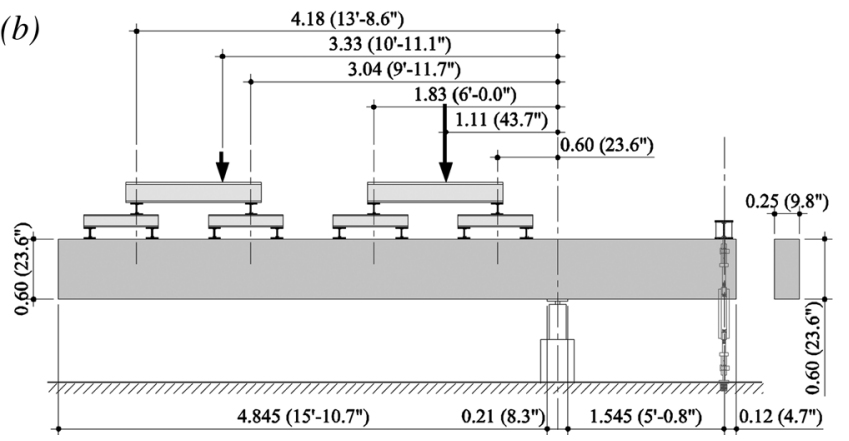

(c)
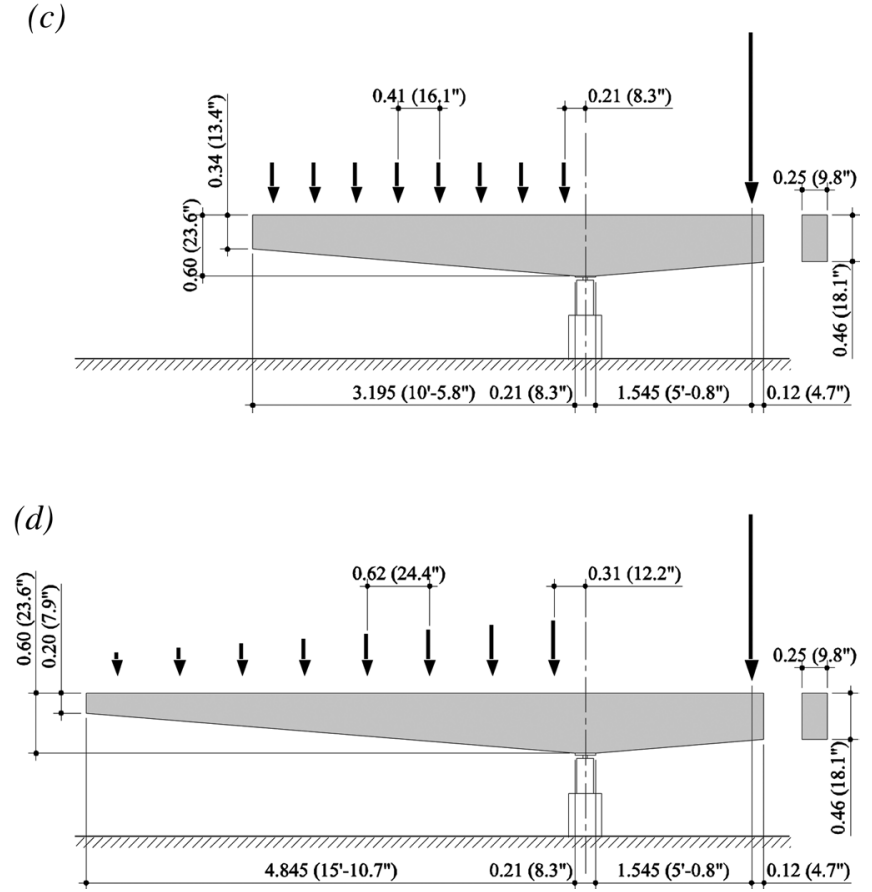

Fig. 3-Tested specimens: (a) test setup for Specimens CR (uniform/point load-constant depth); (b) test setup for Specimens CT (triangular/point load-constant depth); (c)forces and dimensions of Specimens VR (uniform/point load-tapered); and (d) forces and dimensions for Specimens VT (triangular/point load-tapered). (Note: Dimensions in mm [in.].)
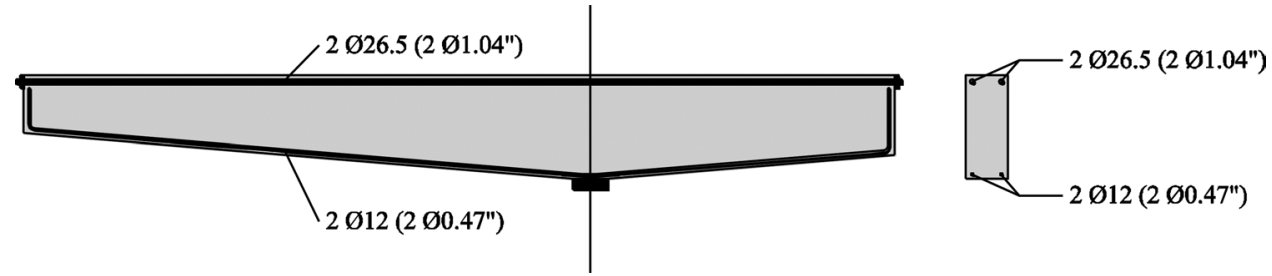

Fig. 4-Reinforcement layout. (Note: Dimensions in mm [in.].)

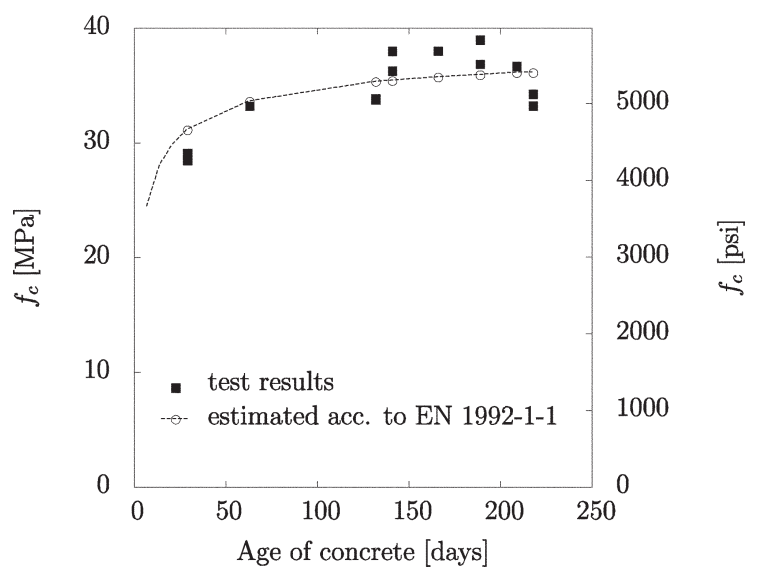

Fig. 5-Evolution of concrete strength with time.

magnitude was chosen to simulate a constantly distributed load or a triangular load (refer to Fig. 3).

The load was introduced by means of two $500 \mathrm{kN}$ (112 kip) jacks, applied on the long cantilever. Load was increased by increments of $25 \mathrm{kN}$ (5.6 kips) until $100 \mathrm{kN}$ (22.5 kips) and by increments of $10 \mathrm{kN}$ (2.25 kips) thereafter. After each load increment, crack development on the specimen was marked and recorded. Each test took approximately 3 hours to be performed. Both jacks transferred the same load in tests with uniform load (CR1-2/VR1-2), whereas in the tests with triangular loading, the jack closest to the central support carried 3/4 of the load while the other jack carried the remaining fourth. Figure 3 describes the way the load was applied for both types of loading.

\section{Concrete properties}

All specimens were concreted at the same time with concrete coming from the same batch with a target 28-day specified strength of $25 \mathrm{MPa}$ ( $3600 \mathrm{psi}$ ). The cement content of concrete was $320 \mathrm{~kg} / \mathrm{m}^{3}\left(539 \mathrm{lb} / \mathrm{yd}^{3}\right)$ with a water-cement ratio $(w / c)$ of 0.54 . The maximum aggregate size of concrete was $20 \mathrm{~mm}$ (0.79 in.). Compression tests were carried out on cylinders $150 \mathrm{~mm}$ (5.91 in.) in diameter and $300 \mathrm{~mm}$ (11.81 in.) high the day after each test (a total of 13 concrete tests). Figure 5 plots the evolution of the concrete strength with time. Also plotted is the EN1992-1-1 ${ }^{12}$ prediction of strength increase with time for the cement class used (this curve is fitted on the basis of the measured compressive strength and is used later in the analysis of test results to determine the compressive strength of the specimens [Table 1]). 
Table 1-Concrete age and compressive strength at loading of tested specimens (calculated according to EN-1992-1-12 fitted on basis of experimental values; refer to Fig. 5)

\begin{tabular}{c|c|c}
\hline Test & Concrete age, days & $f_{c}, \mathrm{MPa}(\mathrm{psi})$ \\
\hline CR1 & 29 & $31.1(4500)$ \\
\hline CR2 & 63 & $33.6(4870)$ \\
\hline VR1 & 132 & $35.3(5110)$ \\
\hline VR2 & 141 & $35.4(5130)$ \\
\hline VT1 & 166 & $35.7(5170)$ \\
\hline VT2 & 189 & $35.9(5200)$ \\
\hline CT1 & 209 & $36.1(5230)$ \\
\hline CT2 & 218 & $36.1(5240)$ \\
\hline
\end{tabular}

Table 2-Shear force at failure (due to external forces and self-weight) at face of support

\begin{tabular}{c|c|c|c}
\hline \multirow{2}{*}{} & \multicolumn{2}{|c|}{$V_{R}, \mathrm{kN}$ (kips) } & \multirow{2}{*}{$V_{R, d i} / V_{R, p o}$} \\
\cline { 2 - 3 } & Point load $V_{R, p o}$ & Distributed load $V_{R, d i}$ & 1.32 \\
\hline CR2 & $132(29.7)$ & $174(39.1)$ & 1.23 \\
\hline VR1 & $154(34.6)$ & $190(42.7)$ & 1.59 \\
\hline VR2 & $148(33.3)$ & $236(53.1)$ & 1.67 \\
\hline CT1 & $114(25.6)$ & $240(54.0)$ & 2.11 \\
\hline CT2 & $149(33.5)$ & $308(69.2)$ & 2.07 \\
\hline VT1 & $118(26.5)$ & $300(67.4)$ & 2.54 \\
\hline VT2 & $141(31.7)$ & $250(56.2)$ & 1.77 \\
\hline
\end{tabular}

\section{Measurements and load introduction}

The reactions were measured by means of load cells located at each support (two under the central support and two at the back stay [short cantilever]). The load applied at the jacks was recorded by the central hydraulic pressure and was consistent with the measured reactions (differences remaining less than $3 \%$ in all cases). The deflections of the cantilever were also recorded by means of extensometers located at midspan, cantilever tip, and at the back stay cross section.

\section{Test results}

The cantilever beams were tested at different ages, as shown in Table 2, performing both tests on the same specimens in the same day. All tests failed in a brittle manner by shear prior to yielding of the tensile reinforcement. Table 2 summarizes the results of the tests in terms of the total shear force acting at the face of the support region at failure. The total shear force accounts for self-weight of the member and of the weight of the loading arrangement (Table 2). As can be seen, the test results show a significant influence of the type of loading. For constant depth members, the shear force is approximately $27.5 \%$ higher (32\% and $23 \%$ ) for members subjected to uniformly distributed loading than for members subjected to point loading, and $109 \%$ higher (107\% and $111 \%$ ) for members subjected to triangular loading, also with respect to point load results.

Figure 6 shows the location and shape of the critical shear cracks of the various tests. For tests subjected to distributed loading, it can be noted that in some cases the critical shear

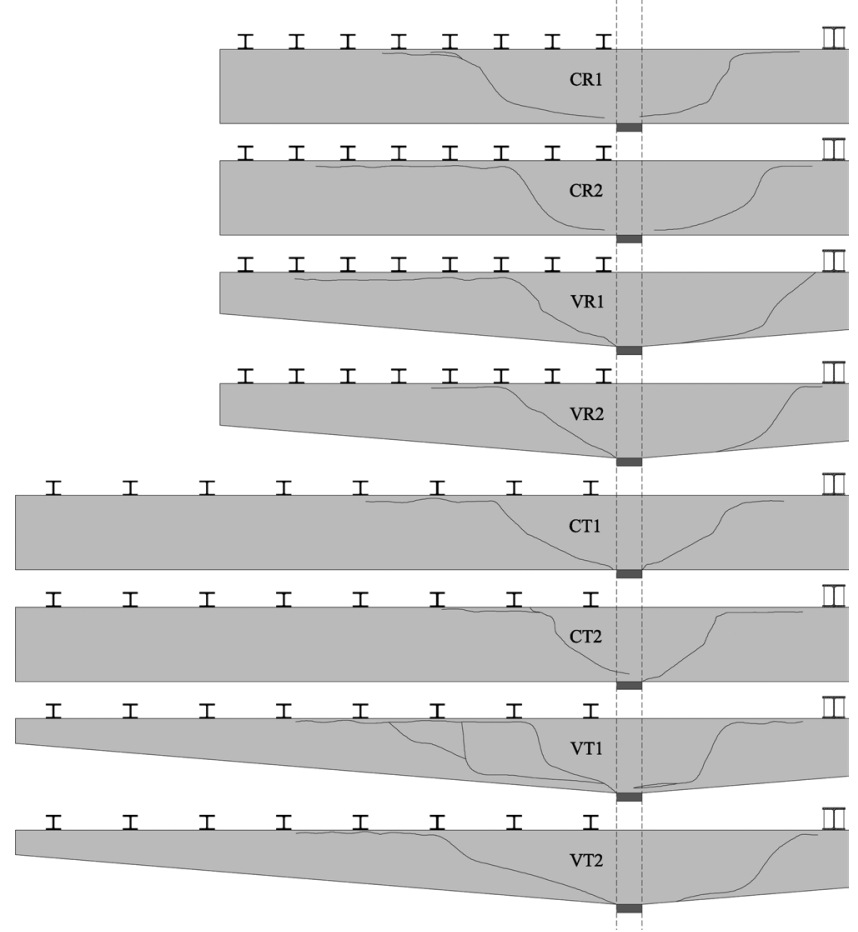

Fig. 6-Shear-critical cracks for each beam.

crack developed between the first and the second applied loads, whereas for others it developed between the second and the third or even third and fourth loads (influencing the number of loads that could be carried by direct strut action).

\section{DISCUSSION OF TEST RESULTS}

Two important effects were investigated with the tests performed: the variable depth and the direct strut action of loads. Direct strut action of the load occurs near the support region, where the struts carrying loads are not intercepted by the shear crack, leading to failure, and thus do not concur to the shear force that has to be carried through it (refer to Fig. 7(a)). Typically this is accounted for in design by neglecting or by reducing loads near supports. ${ }^{12}$

With respect to the effect of variable depth, its influence can be understood with the help of Fig. 7(a) and (b). According to the standard beam theory, and for cantilevers with an inclined soffit, the shear force resisted by the web can be reduced accounting for the vertical component of the compression chord force ${ }^{17} V_{\text {chord }}$. This term has been experimentally acknowledged by some researchers. ${ }^{9,11}$ It should be noted that, according to the proposed model, it accounts only for the loads applied outside the direct support region. This is justified because the force on the compression chord is not influenced by directly strutted loads (refer to Fig. 7(a)).

The influence of these two effects (direct strut action and inclination of compression chord) on the strength of the tested beams can be clearly observed. With respect to direct strut action of the loads, it can be noted that for members with constant thickness, the failure load significantly increased when uniformly distributed or triangular loads were applied (refer to the previous section and Table 2). This clearly confirms that loads near the support region do not concur to the shear that has to be carried by the critical shear crack and can thus be reduced or neglected. 
(a)

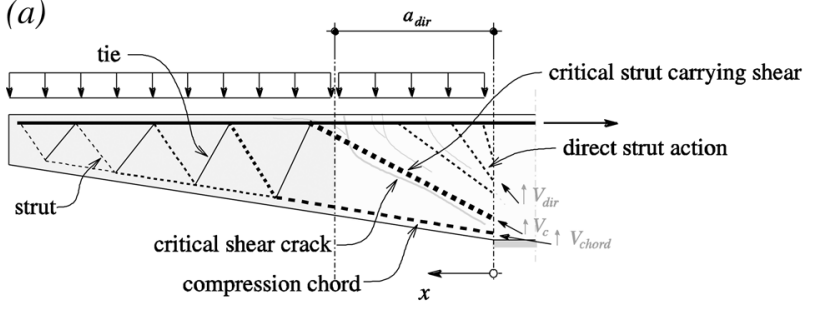

(b)

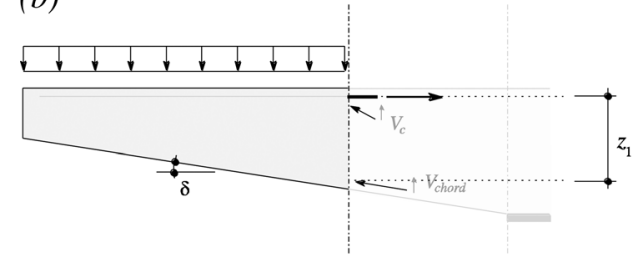

(c)

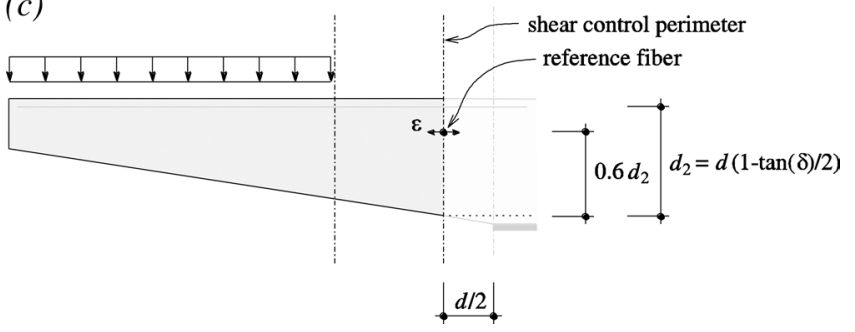

Fig. 7-Shear-transfer actions in slender beam without stirrups: (a) load-transfer action and region for calculation of direct support contribution $\left(\mathrm{V}_{\mathrm{dir}}\right)$; $(b)$ section for calculation of contribution of compression chord $\left(\mathrm{V}_{\text {chord }}\right)$; and (c) section and loads for calculation of $\mathrm{V}_{\mathrm{c}}$.

With respect to the inclination of the compression chord, specimens subjected to a single concentrated load (at approximately $3 d$ ) showed no significant influence for tapered geometries. This is explained by the fact that the load was rather close to the support and the inclined compression zone could only be partly activated (justifying values of parameter $a_{d i r}$ up to $3 d$ ). On the contrary, for the cantilevers subjected to uniform loading, the increase on the strength with the inclination of the compression chord can be clearly observed (an approximately $30 \%$ increase with respect to constant thickness members [refer to Table 2]). The members subjected to triangular loading, however, are less influenced by this fact, as the largest loads were applied near the supports and the direct strut action was mostly governing.

\section{SHEAR STRENGTH OF MEMBERS SUBJECTED TO DISTRIBUTED LOADING ACCORDING TO CSCT}

The increase in the failure load observed in the tests can be understood considering the principles of the CSCT, which are thoroughly presented in Muttoni and Fernández Ruiz. ${ }^{8}$ According to this theory, failure in shear develops when a crack (originated by flexure) develops through the inclined theoretical strut carrying shear, limiting its strength and thus not allowing the member to reach its flexural capacity. The shear strength therefore depends on the width of the critical shear crack (evaluated through the bending moments of the member), as well as on the roughness of the crack surface (evaluated through the maximum aggregate size) where $b$ is the width of the member; $d$ is its effective depth; $f_{c}$ is the compressive strength of concrete measured in the cylinder; $w$ is the opening at the shear-critical region of the crack; and $d_{g}$ is the maximum aggregate size. By adopting the hypothesis ${ }^{8}$ that the width of the critical shear crack is proportional to the deformation $\varepsilon$ at a control fiber (located at $0.6 d$ from the tension reinforcement and calculated assuming a linear-elastic behavior of concrete in compression and no tensile strength ${ }^{8}$ ) times the effective depth of the member $(w \propto \varepsilon \cdot d)$, the following expression results ${ }^{8}$

$$
\begin{aligned}
& \frac{V_{c}}{b \cdot d \sqrt{f_{c}}}=\frac{1}{6} \cdot \frac{2}{1+120 \frac{\varepsilon \cdot d}{16+d_{g}}} \quad \text { [SI units: MPa, mm] or } \\
& \frac{V_{c}}{b \cdot d \sqrt{f_{c}}}=2 \cdot \frac{2}{1+120 \frac{\varepsilon \cdot d}{0.625+d_{g}}} \quad \text { [U.S. customary: psi, in.] }
\end{aligned}
$$

According to this expression, the shear strength depends on the strains (opening of the cracks) of the member. Thus, it allows for a consistent account of the different strengths between cantilevers and simply supported beams subjected to distributed loading, whose bending moments at the shearcritical sections are rather different for the same level of applied shear. Applications of this expression as well as a derivation of design formulas on its basis can be found elsewhere for members failing prior to yielding of the flexural reinforcement ${ }^{8}$ as well as for members failing after development of plastic strains in the flexural reinforcement ${ }^{18}$ (which is pertinent for statically redundant members, such as those shown in Fig. 1(c) to (f)).

The approach of the CSCT can also be consistently used for tapered members. To do so, the strain of Eq. (5) is to be evaluated accounting for the moment at the shear control section due to the loads that are not carried by direct strut action (only loads contributing to the opening of the critical shear crack [refer to Fig. 7(c)]). With respect to the other shear-carrying contributions $\left(V_{d i r}\right.$ and $V_{\text {chord }}$ [refer to Eq. (1)]), they can also be evaluated on the basis of the mechanical model shown in Fig. 7(a).

The shear force carried by direct strut action (thus not contributing to the shear that has to be carried by the critical shear crack) can be directly calculated by integrating loads applied between the support and the distance $a_{d i r}$

$$
V_{d i r}=\int_{0}^{a_{d i r}} q \cdot d x
$$

where $q$ refers to the distributed load on the beam.

With respect to the shear carried by the inclination of the compression chord, it can also be calculated by evaluating $V_{\text {chord }}$ at the same section (a distance $a_{\text {dir }}$ from the border of the support plate [refer to Fig. 7(b)]), where direct strut action of the loads starts to

$$
\frac{V_{c}}{b \cdot d}=\sqrt{f_{c}} \cdot f\left(w, d_{g}\right)
$$

$$
V_{\text {chord }}=\frac{M_{1}}{z_{1}} \tan (\delta)
$$


Table 3-Comparison between theoretical models and test results

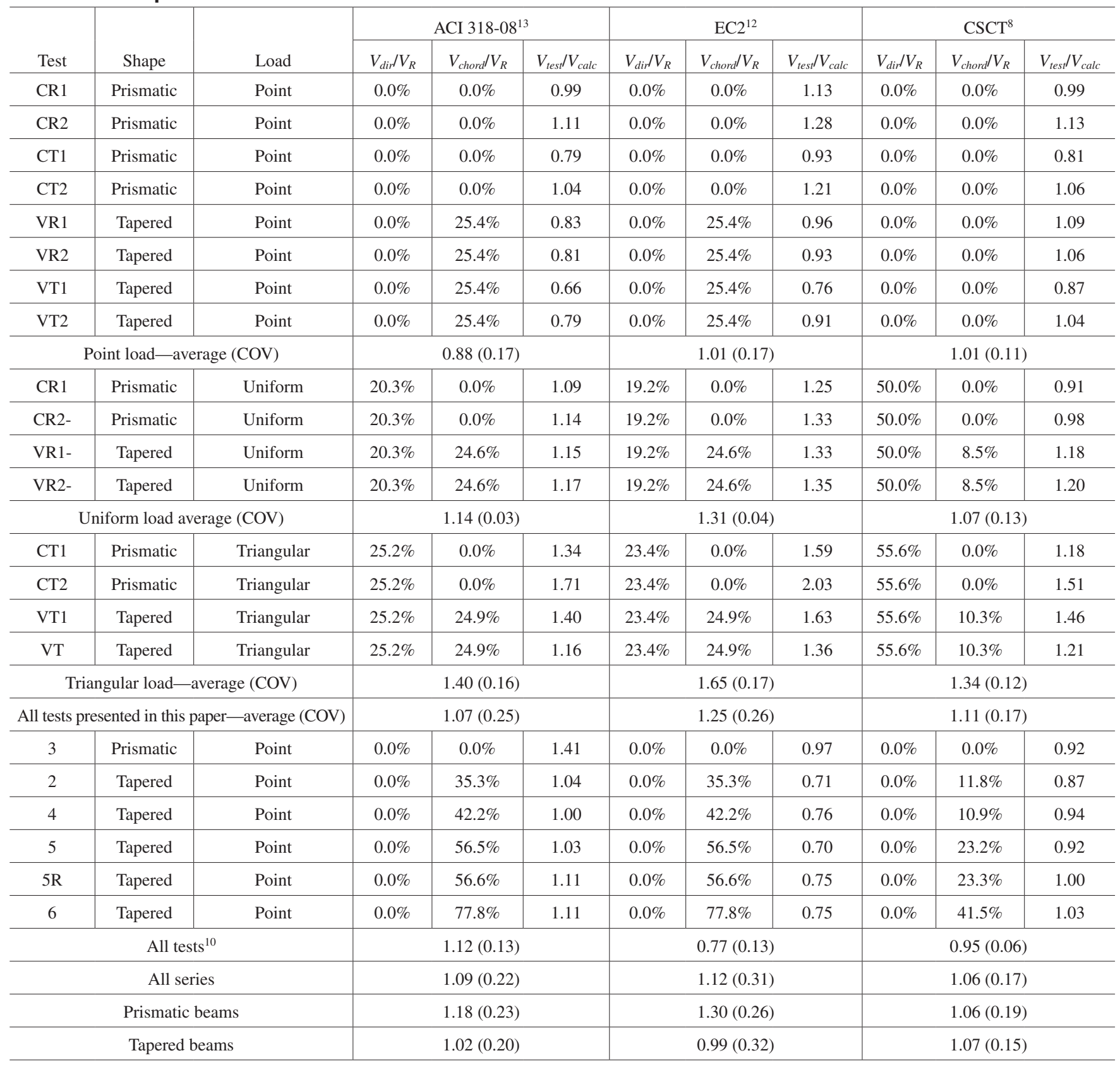

where $z_{1}$ and $M_{1}$ are the lever arm and acting bending moment at the control section where direct strut action starts to develop (Fig. 7(b)), respectively. This is justified because the loads between the edge of the control section and the distance $a_{d i r}$ do not contribute to increasing the force in the compression chord (refer to Fig. 7(a)). It can be noted that Eq. (7) (derived on the basis of the mechanical model in Fig. 7(a) for members without shear reinforcement) differs from Eq. (3a) (derived on the basis of the mechanical model of Fig. 2(b) for members with shear reinforcement) in the section at which the moment and lever arm are to be evaluated as well as on the influence between the $a_{d i r}$-to- $a$ ratio.

\section{SHEAR STRENGTH PREDICTIONS ACCORDING TO ACI 318-08, EC2, AND CSCT}

Comparisons of tests with design codes (ACI 318-08, EC2) and with the critical shear crack theory are given in
Table 3 for the tests presented in this paper as well as similar tests from the literature. ${ }^{10}$ In this table, the percentage of the total shear force carried by direct strut action and by the inclination of the compression chord are also given.

All models consider a reduction of the loads applied near supports (direct strut action). With respect to EC2, loads are reduced between 0 and $2 d$ to account for direct strut action according to the load reduction coefficient $\xi$ shown in Fig. 8. The ACI 318-08 approach presents a stepwise function neglecting (in terms of acting shear) all loads within the face of the support and a distance equal to $d$ (refer to ACI 318-08, Section R11.1.3.1). With respect to the CSCT, and according to its principles, all loads between the support and the distance at which the critical shear crack intercepts the flexural reinforcement can, in principle, be neglected $(\xi$ $=0$ ) for the calculation of the acting shear force at the critical section. From the test results, it has been observed that the 


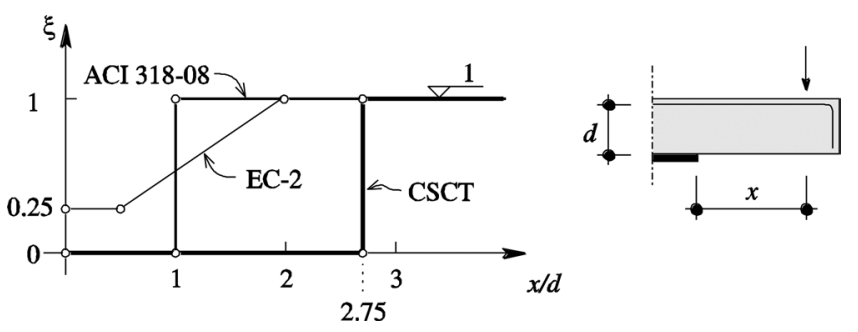

Fig. 8-Load reduction factor $\xi$ accounting for direct strut action according to EC2, ACI 318-08, and proposed law for CSCT for slender members.

value of parameter $a_{d i r}$ depends on the flexural reinforcement ratio and the angle of the tapered beam. For analysis or design purposes, however, adopting a constant value for this length $\left(a_{d i r}=2.75 d\right)$ is sufficiently accurate (Fig. 8). It should be noted that this approach is valid for slender beams $(a / d>2.5$ to 3$)$ with only a fraction of the load applied near the support.

With respect to the shear carried by the compression chord, it can be calculated on the basis of Fig. 7(b). For the CSCT, the value $a_{d i r}=2.75 d$ is again adopted. In addition, the force in the compression chord is calculated assuming that the concrete behaves linearly in compression and carries no stress in tension (in accordance to CSCT hypotheses ${ }^{8}$ ). For ACI 318-08 and EC2, this contribution has been calculated (in bending and shear) for the section at the face of the support (where the tip of the critical shear crack is located over the compression zone [Fig. 6], indicating that the compression chord can carry a fraction of the shear force due to its inclination).

The results of Table 3 show that all models provide relatively good estimates of the strength for failures under point loading of prismatic beams. For tapered beams under point load, however, ACI 318-08 and EC2 overestimate the strength. This is mostly due to the choice of the calculation of $V_{\text {chord }}$ at the section at the face of the support (with a minimum value of measured-to-calculated strength ratio of 0.66 for ACI $318-08$ and 0.76 for EC2).

For specimens subjected to uniform or triangular loading, the predictions are somewhat coarse, especially for EC2 and ACI 318-08. Calculations for ACI 318-08 were performed using Eq. (11-3) of that code. It should be noted that Eq. (11-5) provides very similar results, with differences smaller than $4 \%$. The CSCT provides the best results, only slightly underestimating the strength of tapered members subjected to uniform and triangular loading.

\section{CONCLUSIONS}

This study presents the results of an experimental investigation on the shear strength of reinforced concrete slender cantilevers with prismatic and tapered shapes, subjected to point loading, uniform loading, and triangular loading. Based on the results of this experimental investigation, the following conclusions can be drawn:

1. There is a significant effect of the type of loading on the shear capacity of slender RC members without shear reinforcement.

2. The behavior and shear strength of cantilevers are very different from that of simply supported beams subjected to distributed loading due to the fact that the strains and crack width at the shear critical regions are very different (maximum shear and bending moments in cantilevers, maximum shear but limited bending moments in simply supported beams). This fact, however, is not acknowledged by many codes of practice.

3. For the constant-depth cantilevers tested, the same elements carried $27 \%$ more load for uniformly distributed loading than for point loading, and more than $100 \%$ for triangular loading than for point loading. In the case of variable depth, the increase on the load that can be carried is $63 \%$ for distributed loading and, again, more than $100 \%$ for triangular loading.

4. Regarding the positive effect of variable-depth members (inclination of compression chord carrying shear), this phenomenon plays a significant role in members without shear reinforcement only for loads applied at a certain distance to the support (approximately 2.5 to 3 times the effective depth of the member).

5. A comparison of test results to design approaches (ACI 318-08, EC2, and the CSCT) shows that best predictions are obtained using the CSCT. This theory consistently accounts for the various shear-transfer actions (direct strut action and inclination of compression/tension chords) and for the strains developing in the shear-critical region.

The significance of this topic in structural concrete encourages further investigations that provide more experimental results (completing those of this paper) to improve and refine the theoretical and mechanical models discussed in this study.

\section{ACKNOWLEDGMENTS}

The authors wish to express their gratitude and sincere appreciation to the following people, companies, and official entities that have made this research possible: The Spanish Ministry of Education for funding this program as part of research project BIA-2006-14291; J. Sánchez (DRAGADOS) for providing the formwork for the beams; F. Martínez (DYWIDAG) for providing the high-strength bars; H. Ortega (CELSA) for providing the mild reinforcement; F. García (HYMPSA) for providing the concrete mixture; H. Corres (UPM) for his help and encouragement; J. Torrico (UPM) for preparing the test setup; and S. Lips (EPFL) for drawing the figures.

\section{NOTATION}

$a$

$a_{d i}$ $b$ $d$ $d_{2}$

$d_{g}$

$\begin{aligned} V_{\text {calc }} & =\text { calculated shear strength } \\ V_{\text {chord }} & \text { shear force carried by inclination of compression chord }\end{aligned}$

$V_{d i r}=$ shear force carried by direct strut action

$V_{R}=$ shear strength

$V_{R, d i}=$ shear strength of specimen subjected to distributed loading

$V_{R, p o}=$ shear strength of specimen subjected to point loading

$V_{s}=$ shear force carried by transverse reinforcement

$V_{\text {test }}=$ measured shear strength

$w \quad=$ opening at shear-critical region of crack

$x=$ coordinate

$z \quad=$ inner lever arm at face of support

$\delta \quad=$ inclination of soffit of cantilever

$\varepsilon \quad=$ strain at control depth

$\rho \quad=$ longitudinal reinforcement ratio

$\xi \quad=$ load reduction factor accounting for direct strut action

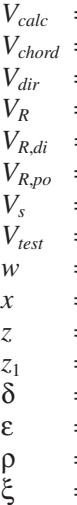

$=$ distance of direct support region

th of member

$=$ effective depth at shear-resisting control section

$=$ maximum aggregate size

eylinder

- distributed load $z_{1}=$ inner lever arm at section where direct support starts to develop

shear span (for distributed load, distan

$=$ bending moment at section where direct support starts to develop

shear force at face of support of specimen (accounting for external - 


\section{REFERENCES}

1. Leonhardt, F., and Walther, R., "Shear Tests on Single Span Reinforced Concrete Beams with and without Shear Reinforcement Investigating Shear Transfer Actions and Maximum Shear Strength (Schubversuche an einfeldrigen Stahlbetonbalken mit und ohne Schubbewehrung zur Ermittlung der Schubtragfähigkeit und der oberen Schubspannungsgrenze)," Deutscher Ausschuss für Stahlbeton, Wilhelm Ersnt \& Sohn, Berlin, Germany, 1962, 83 pp. (in German)

2. Krefeld, W. J., and Thurston, C. W., "Studies of Shear and Diagonal Tension Strength of Simply Supported Reinforced Concrete Beams," ACI Journal, Proceedings V. 63, No. 4, Apr. 1966, pp. 451-476.

3. Cossio, R. D., and Siess, C. P., "Behavior and Strength in Shear of Beams and Frames without Web Reinforcement," ACI Journal, Proceedings V. 56, Feb. 1960, pp. 695-735.

4. Aoyagi, Y., and Endo, T., "Ultimate Shear Capacity of Continuous RC Beams Subjected to Distributed Loading," Proceedings, Fourth East AsiaPacific Conference on Structural Engineering and Construction, Seoul, South Korea, 1993, pp. 727-732.

5. Brown, M.; Bayarak, O.; and Jirsa, J., "Design for Shear Based on Loading Conditions," ACI Structural Journal, V. 103, No. 4, July-Aug. 2006, pp. 541-550.

6. Padilla, P., "Influencia de la distribución de la carga en la capacidad resistente a cortante en elementos sin armadura transversal. Estudio teórico y experimental," PhD thesis, Universidad Politécnica de Madrid, Madrid, Spain, 2008, 456 pp.

7. Shioya, T., and Okada, T., "The Effect of the Maximum Aggregate Size on Shear Strength of Reinforced Concrete Beams," Proceedings, Japanese Concrete Institute, 1985, pp. 521-524.

8. Muttoni, A., and Fernández Ruiz, M., "Shear Strength of Members without Transverse Reinforcement as a Function of the Critical Shear Crack Width," ACI Structural Journal, V. 105, No. 2, Mar.-Apr. 2008, pp. 163-172.
9. Stefanou, G. D., "Shear Resistance of Reinforced Concrete Beams with Non-Prismatic Sections," Engineering Fracture Mechanics, V. 18, No. 3, 1983, pp. 643-666.

10. Macleod, I. A., and Houmsi, A., "Shear Strength of Haunched Beams without Shear Reinforcement," ACI Structural Journal, V. 91, No. 1, Jan.Feb. 1994, pp. 79-89.

11. Tena-Colunga, A.; Archundia-Aranda, H. I.; and GonzálezCuevas, O. M., "Behavior of Reinforced Concrete Haunched Beams Subjected to Static Shear Loading," Engineering Structures, V. 30, No. 2 , 2008, pp. 478-492.

12. CEN, "EN-1992-1-1: Eurocode 2. Design of Concrete StructuresPart 1-1. General Rules and Rules for Buildings," prEN1992-1-1, 2004, $225 \mathrm{pp}$.

13. ACI Committee 318, "Building Code Requirements for Structural Concrete (ACI 318-08) and Commentary," American Concrete Institute, Farmington Hills, MI, 2008, 473 pp.

14. Kani, M. W.; Huggins, M. W.; and Wittkopp, R. R., "Kani on Shear in Reinforced Concrete," Department of Civil Engineering, University of Toronto, Toronto, ON, Canada, 1979, 97 pp.

15 Muttoni, A., and Fernández Ruiz, M., "Shear in Slabs and Beams: Should They be Treated in the Same Way?" Fédération Internationale du Béton (fib) Bulletin, No. 57, 2010, pp. 105-128.

16. Vaz Rodrigues, R.; Fernández Ruiz, M.; and Muttoni, A., "Punching Shear Strength of R/C Bridge Cantilever Slabs," Engineering Structures, V. 30, No. 11, 2008, pp. 3024-3033.

17. Mörsch, E., Reinforced Concrete Construction, Theory and Application (Der Eisenbetonbau, seine Theorie und Andwendung), third edition, Verlag von Konrad Wittwer, 1908, 376 pp. (in German)

18. Vaz Rodrigues, R.; Muttoni, A.; and Fernández Ruiz, M., "Influence of Shear on the Rotation Capacity of Reinforced Concrete Plastic Hinges," ACI Structural Journal, V. 107, No. 5, Sept.-Oct. 2010, pp. 516-525. 